\title{
Research and application of nuclear power plant in-service inspection information management platform
}

\author{
CHEN Yan-hui ${ }^{1, *}$, Li tian ${ }^{2}$, XUE Dong-lin ${ }^{3}$ \\ 1-3 Suzhou Thermal Power Research Institute Co., Ltd. Suzhou, China
}

\begin{abstract}
In-service inspection is one of the important means to ensure nuclear safety, and the current manual management model has been difficult to adapt to the high requirements of nuclear power development. For example, there have been problems such as inconsistency of key data information, difficulty in statistical analysis of inspection results, lack of or untimely experience feedback. Through the research and application of the in-service inspection technology management platform, it focuses on the platform design, business architecture, and key technologies in the actual development process. The application of the platform is a further upgrade of the in-service inspection management model. It can further enhance the advantages of information management, improve the management efficiency and level of in-service inspection of nuclear power plants, and escort the safe operation of nuclear power plants.
\end{abstract}

\section{Introduction}

During the operating life of a nuclear power plant, a series of in-service inspection activities must be carried out on mechanical pressure equipment in accordance with the requirements of laws and regulations [1]. Its purpose is to continuously supervise the quality of various operating equipment and systems of nuclear power plants. For example, it can supervise and control the defects that may exist in the equipment, including those formed during the manufacturing and installation stages, and the expansion of defects due to fatigue and corrosion after being put into operation.

In-service inspection is a series of long-term and complex tasks, including laws and regulations, document management, plan arrangement, on-site inspection implementation, result report preparation, defect tracking treatment, personnel qualification authorization ${ }^{[2]}$. Since the quality of this work-related activity directly affects the safety of the unit, it must be carried out in accordance with laws and regulations, and the activity record must be available for the entire life of the power plant. Therefore, the in-service inspection and management of nuclear power plants must meet the requirements of compliance, accuracy and traceability ${ }^{\text {[3- }}$ 5].

At present, most of the nuclear power plants in operation in China, paper-based manual management is applied to all aspects of the in-service inspection work. With the increase of running time and the continuous improvement of management level, the problems brought by a series of paper-based manual management models have gradually become prominent. Based on the analysis of the original in-service inspection management work mode, this article first proposed the use of the in-service inspection technology management platform to realize the in-service inspection information management of nuclear power plants. It focuses on the key points of the actual development process, and finally realizes the upgrade of the in-service inspection management tools, and maximizes the advantages of the information management of the in-service inspection of nuclear power plants.

\section{Current status of in-service inspection management in nuclear power plants}

With the continuous development of China's nuclear power industry, it had evolved from the original singlesite single-reactor type to the current multi-base group plant and multi-reactor type. Judging from the implementation of pre-service and in-service inspections of various nuclear power bases, the number of annual refueling overhauls had increased from 5 times a year in 2013 to 16 times in 2020 . With the continuous increase of operating units and the increasing number of inservice inspection records, several typical problems under the traditional in-service inspection management model has become increasingly prominent. as follows:

(1) According to the requirements of regulations, the original records, data, and inspection results of the inservice inspection of nuclear power plants should be kept within the lifetime. Statistics show that there are more than 8,000 inspection items required by regulations for a single unit, and the average number of inspection reports for each unit overhaul is as many as 2,000 pages. Therefore, during the operating life of nuclear power plants, there are problems in the in-service inspection of key equipment such as huge data volume, multi-base

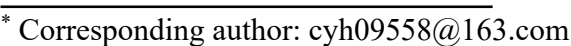


decentralized management, complex technical parameters of multi-reactor type, and difficult to use inspection results.

(2) In order to finely manage the inspection items, the power station has established a complete in-service inspection outline document system, including the inservice inspection outline, pro-service inspection outline, outline of in-service plan (statutory/non-statutory), 10year plan, annual overhaul plan, these are shown in Figure 1 below. The inspection requirements and inspection plan of each weld are incorporated into the above documents for tracking. Since the inspection plan information exists in multiple outlines, the outline documents are not linked to each other when manually modified, resulting in inconsistent planning status of the outline documents. This makes the plan status inconsistent with the on-site implementation status, and it is difficult to find inaccurate information on the parts to be inspected in the outline.

(3) For historical in-service inspection result information, data and inspection results have not yet been shared among power stations. With the increase in the number of overhauls, a large amount of accumulated inspection result data cannot be systematically analyzed and fully utilized. Especially for defect tracking and trend analysis, there is a lack of support and application of big data, and the common problems of many power stations cannot be dealt with.

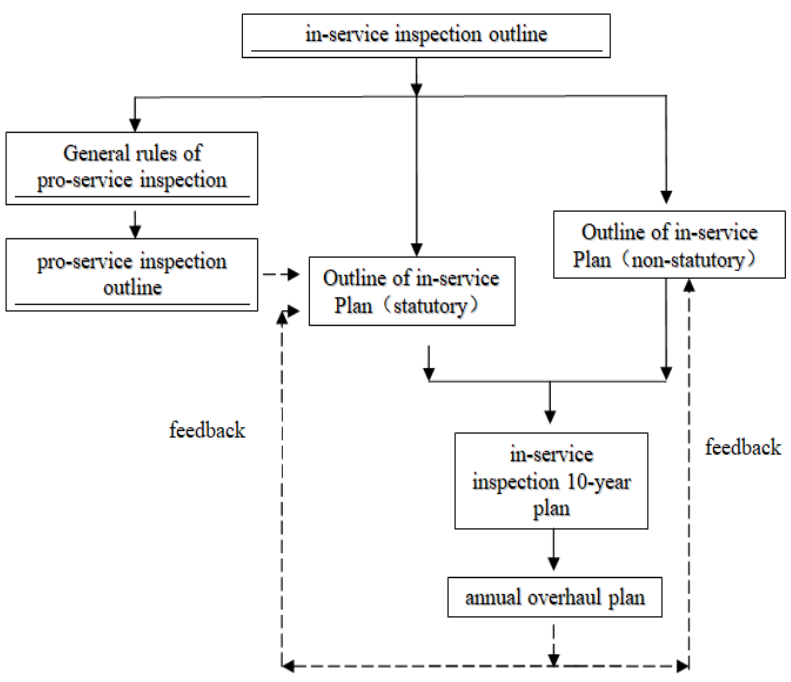

Fig1 In-service inspection outline document system

\section{Key points of platform implementation}

\subsection{Management platform design}

The design of the platform directly utilizes the existing server and network resources of the nuclear power plant and follows the infrastructure requirements of the IT department. The platform uses JUD framework, B/S structure, based on LAN, development kit: JDK1.7, server: Tomcat7.0.93, supported browsers: IE10 or higher, Chrome V50 or higher, Firefox V50 or higher; database: b; server operation system: Linux; the development process uses unified authority management,
UBA log management, and BPS workflow management. The architecture selection of the new platform is shown in Figure 2 below.

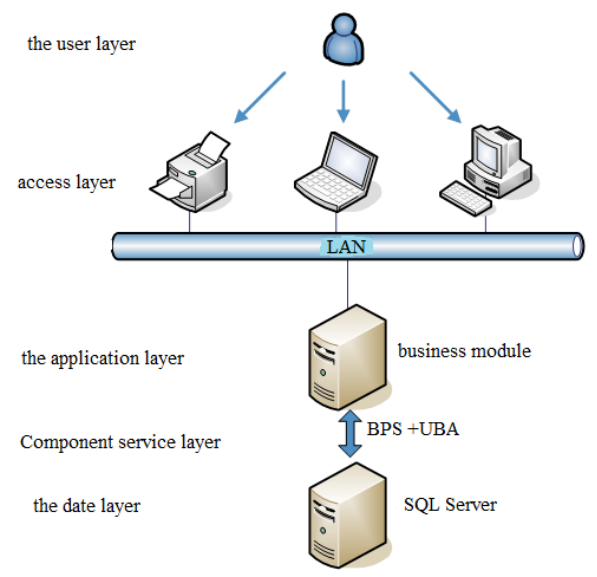

Fig 2 Architecture selection of the new platform

\subsection{Overall business structure}

The in-service inspection technology management platform is mainly divided into six functional modules, namely outline and plan management, daily and overhaul management, nuclear island service inspection parts management, conventional island and BOP service inspection parts management, welding management and knowledge base. In addition, there are two auxiliary modules for the home page and system configuration. The overall business structure of the new platform are shown in Figure 3 below. This platform is used by multinuclear power bases, which can satisfy the simultaneous online visits of in-service inspection professionals from different bases.

(1) Homepage: It contains links to frequently used websites and personal workbenches. Among them, the personal workbench is mainly used for the preparation and approval of processes in the platform.

(2) Outline and plan management: covering the two major business sectors of conventional islands and nuclear islands, including outline management, ten-year plan management, special inspection plan, legend management, special tool management, inspection program management and annual plan. This module is mainly used for the maintenance and update of nuclear island and conventional island in-service inspection outline and the generation of annual plan. It is the core of the platform.

(3) Daily and overhaul: including overhaul management, qualification and authorization management, and container hydraulic test management. The qualification and authorization management includes non-destructive testing qualification management, special verification project personnel management, and visual inspection of nuclear island maintenance, covering the entire process management of nuclear power in-service inspection personnel from obtaining certificates to having authorization.

(4) Service inspection parts management: It is divided into 2 modules of nuclear island, conventional 
island and BOP service inspection parts management, including basic information of service inspection parts, defect display management, service inspection report and result data management. This module covers the historical in-service inspection result data of each nuclear power unit from pre-service inspection to previous overhauls, and can provide big data input and support for the defect analysis of historical inspection results.

(5) Welding management: Welding applications are submitted on the platform and a welding quality plan is created, including calling the welding application form, welding procedure card, welding consumables and other information. After pre-dispatching welders and passing the approval, the welding quality plan can be printed. When on-site welding is completed, non-destructive testing is required. It realizes closed-loop management of the entire process from welding application to postwelding non-destructive testing.

(6) Knowledge base: including laws, regulations, standards, internal and external experience feedback. It is a summary of the knowledge system related to inservice inspection.

(7) System settings: including public dictionary management, process configuration, base management, cycle management, and authority settings. It mainly cooperates with the management of plant bases and units, the generation of outline and plan management data, and the configuration of processes.

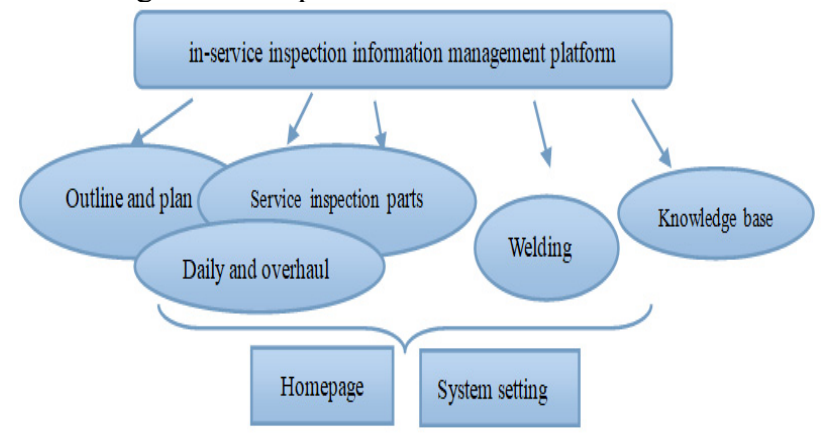

Fig 3 Overall business structure of the new platform

\subsection{Key technologies for platform implementation}

(1) Unified authorization management. By calling the unified authority system of the nuclear power plant, on the one hand, it can control the data operation process of each module of the platform, and on the other hand, it can control the user's access and operation authority to the data of each module, ensuring the security of the data in the platform.

(2) The establishment of platform relevance. The outline plan management module digitizes a large number of inspection items in the outline document and sets up a separate plan data table. Develop an inspection plan for each weld and use it as the only plan source for the platform. The plan information in the outline is quoted from the plan data sheet to solve the problem of inconsistency in the plan status of the outline file during manual management. At the same time, with powerful report import and export functions, it can meet the dual needs of data management and paper-based management. For example, when the plan data is modified in outline of in-service plan (statutory/non-statutory), the 10-year plan is update in real time. the specific execution process is shown in figure 4 below.

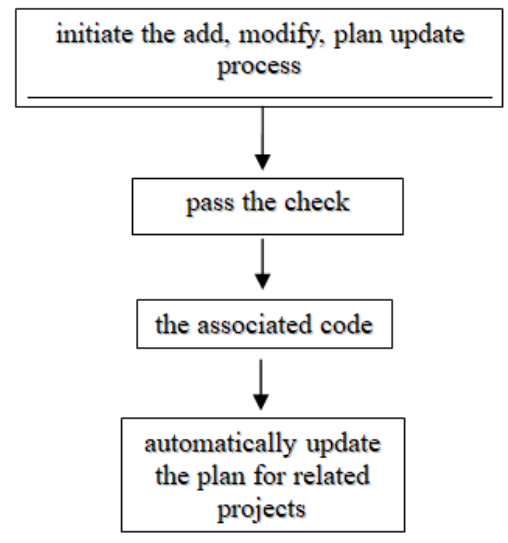

Fig 4 A set of processes for plan update

(3) Reuse of historical in-service inspection result data. It systematically and structured the classification and storage of the inspection method data and inspection results. The time axis can clearly show the actual development trend of the display or defect over the years, and the abnormal data in the system can be retrieved in real time through the system. At the same time, data processing methods such as data fitting, data statistics, and matrix theory are used to analyze and research displays or defects.

(4) Preparation and import of initial data in the platform. The relevance and traceability of data in the platform is based on high-quality initial data. Therefore, in order to ensure the correctness of initial data including outline data, plan data and inspection results, It needs to be carefully verified in conjunction with outline files, drawing, design documents and inspection reports. The data preparation and inport process is shown in figure 5 below.

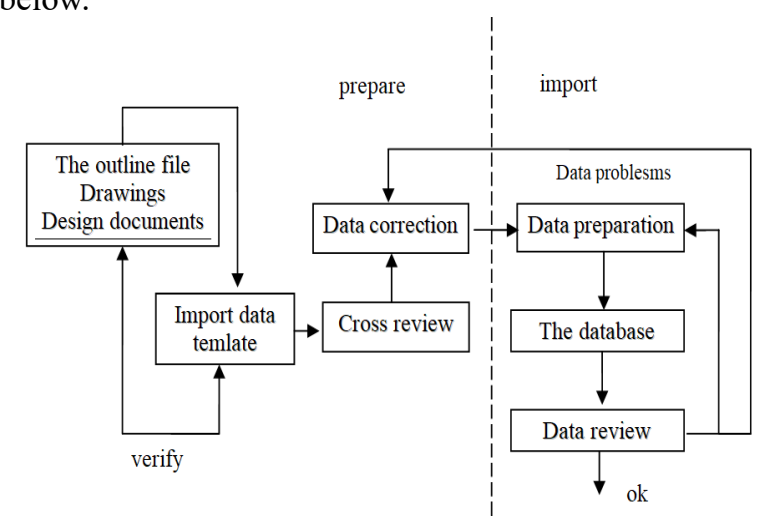

Fig 5 Preparation and import of initial data

\section{Application feedback}

At present, the in-service inspection technology management platform has been successively applied in various nuclear power bases. It has realized the 
informatization of the outline, plan, overhaul management, personnel qualification authorization, vessel hydraulic test, nuclear island and conventional island service inspection results, welding management, etc. The advantages of integrated management are obvious, as follows:

(1) Labor costs are saved, and the accuracy of data is greatly improved. The platform has multiple functions, including outline and plan management, daily and overhaul management, service inspection parts management, welding management and other core functional modules, covering the two major business sectors of nuclear island and conventional island. It liberates the professionals involved in the in-service inspection of nuclear power plants from the complicated paper management mode and reduces labor costs. Through information-based module management, interactive links between different modules, and fullprocess control, the accuracy of the submitted data is greatly improved, and the traceability of the in-service inspection data is realized.

(2) Form a complete database of non-destructive inspection history inspection results. For nuclear island and conventional island service inspection components, the original data input of historical in-service inspection results is formed through the defect display tracking of multiple overhauls and the summary of in-service inspection result data. Through the centralized management of the historical inspection result data of each unit and the systematic analysis of different method data and inspection results, the utilization value of the data is enhanced. It promotes non-destructive testing to non-destructive evaluation, and provides data support for equipment reliability evaluation, life management, and aging research.

\section{5 concluding remarks}

In-service inspection is one of the important means to ensure nuclear safety. The traditional in-service inspection management mode urgently needs to be further optimized and upgraded. The application of the in-service inspection technology management platform has realized the information management of the inservice inspection. Compared with the original paperbased management model, the management efficiency of the platform is significantly improved, which greatly meets the diversified management needs of nuclear power plant in-service inspection management. As a reliable, convenient and efficient information management tool, it protects the safe operation of nuclear power plants.

\section{References}

1. LIU Wei. (2020) Development of In-Service Inspection nondestructive testing Technology for nuclear power plant.J. Science \& Technology Vision., 197-199.

2. LIU Xiang-mei. (2017)Discussion on the document management of In-Service Inspection for nuclear power plant. J.Science \& Technology Information., 01: 95-96.

3. WANG Wei - guo. (2018)Management and optimization of M310 reactor nuclear island comprehensive in - service inspection plan. J. Science \& Technology Vision., 210-214.

4. ZHANG Wen-zhe, MA Ben-yu. (2017) Design and implementation of in-service inspection information management platform for nuclear power plant. J. Science \& Technology Vision., (01):341-342.

5. ZhANG Xue-liang, Fan Yan-cheng, Wang Chunyang, Zhou Guo-zheng. (2014) Study and application of Information management system for In-Service inspection of nuclear power plant. J.Science of Telecom., 30:160-16 